\title{
Research on the Training of Interactive Design Concept in the Digital Media Course Teaching
}

\author{
Lu Dong ${ }^{1}$, Robert Willey ${ }^{2}$ \\ ${ }^{1}$ Harbin Institute of Technology, Harbin, Heilongjiang Province, 150001 \\ ${ }^{2}$ School of Music, Ball State University, Muncie 47306, USA
}

Keywords: digital media course teaching; Sino-American comparison; interaction design concept

\begin{abstract}
The teaching of digital media courses is an important curriculum system proposed and constructed based on the extensive application of information technology and science and technology in social construction. The requirements for teachers to organize teaching activities are relatively high. Teachers need to be able to combine the needs of the development of teaching in the new era. This paper starts with the teaching of digital media courses and compares the teaching of digital media courses between China and the United States, proposes measures for cultivating students' interaction design concepts in teaching activities in the new era, and hopes to improve the actual effect of teaching activities and provide students with digital media.
\end{abstract}

\section{Introduction}

The time for digital media course teaching in our country is relatively short, and there is a lack of perfect theoretical guidance in the actual teaching process, which leads to certain problems and severely limits the improvement of teaching quality. In the new period, in the process of teaching reform, we can analyze the teaching of American digital media courses, and actively explore the measures for cultivating students' interactive design concepts in light of the experience of American school teaching reforms. We strive to improve the teaching status quo in a gradual and orderly manner and realize the cultivation of high-quality talents. The goal is to create good conditions for the students' future career development.

\section{Comparative Analysis of the Teaching of Digital Media between China and the United States}

For a long time, American colleges and universities have stepped up their attention to the teaching of digital media courses, and have made corresponding practical explorations in this regard, and have achieved some results. In recent years, our country has also begun to recognize the importance of teaching digital media courses, and in the teaching and learning activities to strengthen the study of curriculum teaching activities, to provide support for the implementation of curriculum reform. The following is a comparative analysis of the actual situation of the teaching of digital media between China and the United States. The results of comparative analysis will provide theoretical guidance for the teaching of digital media in China:

First of all, from the perspective of students, the relevant majors involved in the American digital media curriculum belong to the "music media industry". The main talent training work is divided into two directions, namely, digital media technology and digital media arts, to enhance teaching pertinence. However, according to the situation of enrollment in colleges and universities in our country, during the enrollment of students in colleges and universities, students come from different students of arts and sciences, so some students appear short-leg phenomenon, such as arts students are often difficult to understand technical courses, while arts students have insufficient artistic experience and art literacy. [1]. At the same time, U.S. colleges and universities will organize students to participate in the entrance examination before enrolling students, and add examinations for the vocal music of musical instruments to recruit students who are genuinely interested and 
enhance their quality. The students enrolled in domestic art schools are often divided into two types, namely, learning music from a young age, showing a certain talent and enthusiasm in the music field, and having a low score in cultural courses, and having to choose the students of the Art Institute. University students in our country have complex sources, difficulty in teaching and talent training.

Secondly, from the aspect of curriculum planning, some universities in the United States have long emphasized the importance of music media industry course teaching, and after continuous research and exploration, they have formed a relatively complete curriculum plan that can provide students with relatively scientific teaching guidance. Both theoretical knowledge and practical skills can be well-trained. For example, the entire two-day course was set up for the “Audio-visual-learning" course, which achieved the goal of improving students' sense of sound and hearing [2]. However, the analysis of the teaching situation in China's colleges and universities, some schools still do not have the ability to set up "audiovisual training" program, even if some colleges and universities open, it is often concentrated in one year teaching time. The colleges and universities in China pay more attention to the music theory courses in the curriculum setting. The music practice curriculum is seriously inadequate and can not provide corresponding practical guidance to students. This results in the obvious limitation of the students' learning of the curriculum, and the obvious lack of independent learning ability and independent learning ability of the students. This severely restricted the quality of personnel training in colleges and universities. At the same time, it should be noted that the setting of this curriculum model has made it difficult for students cultivated in universities in our country to independently complete related works. The number of outstanding works is even smaller, and personnel training have remained at a lower level. For example, in the theoretical course teaching, for the "Music Industry Survey", it is often difficult for colleges and universities in our country to truly organize students to participate in surveys, and it is impossible to acquire the corresponding abilities and experiences in practical creations, which leads to a great limitation on students' overall learning.

Finally, look at the status quo of the development of industrial courses. In the process of teaching digital media courses in the United States, the setting of industry courses covers history, and is closely linked with the current state of development of American social art and the development needs of the art industry. With the help of optimization and innovation of industrial course teaching, In accordance with the needs of talents in society to promote the optimization of talent cultivation, the overall goal of personnel training work has been comprehensively promoted, and it has played a role in promoting the employment of students [3]. However, the establishment of industrial courses in universities and colleges in China is often confined to classroom teaching activities. It lacks an organic connection with the status quo of the development of social art industries and the demand for talented people. As a result, the setting of industrial courses lacks scientificity and practicality, and it is difficult to lay the foundation for the optimization of personnel training.

\section{Measures of Training Interactive Design Concept in China's Digital Media Curriculum Based on the Comparative Analysis Results}

On the basis of comparative analysis, we can see that there are still some problems in the current digital media curriculum teaching in China, which greatly limits the employment development of students. Therefore, in the process of exploring teaching reform activities in the new era, we must combine the basic situation of personnel training work. Formulate appropriate teaching organization programs to implement more scientific and effective teaching guidance for students, so that the teaching effects can be comprehensively and systematically enhanced [4]. The specific combination of the needs of students to interact with the design of the reform of the teaching reform measures and found that you can start from the following aspects to develop a relatively scientific teaching organization program:

\subsection{Building a Perfect Teaching Activity System}

Based on the combination of digital media course teaching and developing students' interaction 
design concepts, teachers should clearly recognize that the formation of students' interaction design concepts is closely related to interaction experience and interaction concepts. Therefore, teachers must combine interaction design concepts to cultivate demand for teaching activities. The system is improved, and the teaching ideas of interactive design concepts are integrated into the theory, investigation, practice, performance and other aspects of curriculum teaching. It is truly integrated into the teaching activity system in all aspects of digital media teaching, so that the teaching quality is comprehensively and systematically improved [5]. For example, in the design activities for digital games, teachers can combine the interactions between digital game designers and audience groups to cultivate students' interaction design concepts, and deepen students' understanding from the perspective of design theory. Through investigation and research, students can realize that Digital game design must reflect the interaction needs, and then in the practice of exploration activities will fully reflect the interactive design ideas, and enhance the design effect. In this way, we can improve the quality of teaching by improving the construction of teaching activities, and gradually realize the goal of cultivating high-quality digital media talents, so as to provide corresponding personnel protection for the development of social digital media in China.

\subsection{Explore the Organic Integration of Teaching Activities and Emerging Social Media}

In the process of optimizing and innovating teaching activities of digital media courses, combined with the teaching needs of cultivating student interaction design concepts, teachers can also organically integrate teaching activities with new social media in China on the basis of reform and innovation of teaching activities. The important role of the emerging media in society should be brought into play to provide students with a platform for practical learning. This will create favorable conditions for the integration of theoretical teaching and practical teaching, and effectively promote the overall and systematic improvement of the quality of teaching activities. In the process of concrete exploration of the integration of digital media teaching activities and emerging social media, teachers can share information related to interaction design concepts with students through social platforms such as Wei-blog and We-Chat, enabling students to receive rich theoretical knowledge.[6] On this basis, the teachers arrange training tasks related to student interaction and design training on the Internet, enabling students to use the emerging media platform as a vehicle, actively explore the embodiment of interactive design concepts in digital media, and try to integrate interactive design ideas. In specific practical activities, students' understanding is deepened, and the links between course teaching content and student life are closely related, and the effectiveness of teaching and learning activities is gradually improved, so that students can obtain their own interactive design concepts on the basis of continuous learning and exploration.

\subsection{Teachers Should Gradually Update Their Thinking and Always Put Themselves at the Forefront of Their Profession}

In the teaching activities of digital media courses, cultivating students' interactive design concept has extremely important value, and the comprehensive quality of teachers has an important influence on the training of student interaction design concepts. Therefore, in the context of the new era, based on the need to strengthen students' digital media interaction design concepts, teachers should actively change their own concepts, establish lifelong learning ideas, and provide education guidance to students while always paying attention to the frontier knowledge of the professional and learning and Based on cutting-edge knowledge, we can integrate the most advanced ideas and technologies into classroom teaching activities, reform and innovate the teaching of digital media courses, comprehensively enhance the pertinence and effectiveness of teaching activities, and give play to the role of teacher protection to strengthen digital media.[7]. In the process of teacher participation combined with the practical needs of cultivating student interaction design concepts to participate in teaching reform activities, teachers can participate in the frontier scientific research work of the professional and contact with the most advanced ideas and technologies; on the other hand, they must continue to participate in teacher education activities. Communicate and communicate with excellent experts and scholars and front-line educators, summarize advanced 
digital media teaching experience, reform and innovate the teaching activities to cultivate students' interactive design concepts, and comprehensively improve the actual effect of teaching organization activities, and provide students with comprehensive qualities. The cultivation creates ideal conditions.

\subsection{Students Brainstorm through Investigations to Achieve Teaching Goals in Practice}

In view of the imbalance in the proportion of theoretical teaching and practical teaching in digital media teaching activities, teachers actively guide students in the process of teaching reform activities and can guide students to accept brainstorming teaching guidance on the basis of investigation and practice activities so that students can participate in relevant industries. Deepen ideological understanding based on practice and improve the overall effect of teaching organization activities [8]. In the process of integrating the digital media profession involving related industry teaching content in the reform and innovation of teaching activities, teachers can actively explore the application of brainstorming teaching mode to enable students to deepen their understanding of the digital media industry in their learning and practice, and enable students to learn from The interactive design perspective carries out free research and analysis of the development of the digital media industry, and then issues new ideas and new ideas on the basis of imagination, association and discussion, and makes new ideas in practical activities based on systematic analysis. Imagine conducting verification and gradually realize the basic objectives of teaching and learning activities in practice. In this way, under the influence of brainstorming methods, students' potentials can be stimulated based on the application of teaching resources, and the teaching effects can be comprehensively improved. On the basis of realizing the goal of cultivating student interaction design concepts, the quality of teaching activities and talents can be achieved. The quality of training has been systematically improved.

\subsection{Construct a Flipped Classroom Teaching Model to Enhance Students' Autonomy in Learning}

In the process of integrating digital media teaching with teaching reform measures, teachers can try to introduce a flipping classroom teaching model to provide active and effective guidance to students and create conditions for students to learn independently, so that students can form a pair on the basis of continuous participation in independent inquiry. The profound understanding of digital media interaction design guides students to establish correct interactive design concepts, and on the basis of cultivating students' autonomous learning ability, gradually realizes the goal of teaching organization activities. In the process of actively exploring teaching reforms, teachers can guide students in a systematic analysis of the flipping classroom teaching mode, and provide students with high quality pre-department guidance in combination with the application of the micro lesson teaching mode so that students can learn independently before class. The application of the combined learning resources participates in the interaction design practice and creates the conditions for practice verification for students [9]. On this basis, the key points and difficulties encountered by teachers in summarizing the learning process are discussed together with other students in the classroom. They are also guided by the teachers and can deepen the students' ideological understanding, assist them in building a perfect knowledge system, and further improve them step by step. The practical effect of the teaching organization activities ensures that the training effect of student interaction design concepts can be gradually enhanced.

\section{Conclusion}

To sum up, training students' interactive design concepts in the teaching of digital media courses can further improve the teaching effectiveness and the quality of personnel training, and enhance students' social adaptability, so that the overall quality of students can be significantly improved. Therefore, in teaching and organizing activities, teachers should study the measures for cultivating student interaction design concepts in the teaching activities of digital media courses, enhance the pertinence and effectiveness of teaching, and lay a solid foundation for the future career 
development of students.

\section{References}

[1] Chen Nan. Multi-screen digital animation multimedia interactive system design [J]. Modern electronic technology, 2017 (19) :83-85,90.

[2] Zhao Yijun. Research on Natural Interaction Design of Digital Media[J]. Wireless Network Technology, 2017(4):59-60.

[3] Song Hao, Zhao Xi. Research on interactive design of digital media[J]. Shanxi Youth, 2017(11):283.

[4] Liu Chunmiao. Application of digital media technology in interactive product design - Review of "Digital Media Interaction Design" [J]. News Enthusiast, 2017(1):12.

[5] Li Ge, Zhang Ruijing. Analysis of the characteristics of digital reading and interactive design mode in the era of media immersion[J]. China Publishing, 2017(9):21-24.

[6] Qi Mingyi. Application research of interactive design in the context of big data[J]. Industrial Design, 2017(4): 109,111.

[7] Cai Rixiang. Exploring the development trend of interactive design in the new media art[J]. Industrial Design, 2017(12):12-13.

[8] Mu Bingyu. Transpositional Thinking of Digital Media Interaction Design[J]. New Media Research, 2016(10):115-116.

[9] Li Shihao. Research on Interactive Design of Mobile Advertising in Digital Media Environment[J]. China Packaging, 2016(7):40-42. 